\title{
Group 2 Innate Lymphoid Cells (ILC2s) Are Key Mediators of the Inflammatory Response in Polymicrobial Sepsis
}

\author{
Tristen T. Chun, ${ }^{*}$ Chun-Shiang Chung, ${ }^{*}$ Eleanor A. Fallon, ${ }^{*}$ Noelle A. Hutchins, ${ }^{*}$ Erlyana Clarke, ${ }^{*}$ Anne-Lise Rossi, \\ William G. Cioffi, ${ }^{*}$ Daithi S. Heffernan, ${ }^{* \dagger}$ and Alfred Ayala*
}

From the Division of Surgical Research, * Department of Surgery, and the Division of Trauma and Surgical Critical Care, ${ }^{\dagger}$ Alpert Medical School of Brown University, Rhode Island Hospital, Providence, Rhode Island

\author{
Accepted for publication \\ May 30, 2018. \\ Address correspondence to \\ Alfred Ayala, Ph.D., Rhode \\ Island Hospital, 593 Eddy St. \\ Aldrich 227, Providence, \\ RI 02903. E-mail: aayala@ \\ lifespan.org.
}

\begin{abstract}
Sepsis remains a major public health concern, characterized by marked immune dysfunction. Innate lymphoid cells develop from a common lymphoid precursor but have a role in orchestrating inflammation during innate response to infection. Here, we investigate the pathologic contribution of the group 2 innate lymphoid cells (ILC2s) in a murine model of acute septic shock (cecal ligation and puncture). Flow cytometric data revealed that ILC2s increase in number and percentage in the small intestine and in the peritoneal cells and inversely decline in the liver at 24 hours after septic insult. Sepsis also resulted in changes in ILC2 effector cytokine (IL-13) and activating cytokine (IL-33) in the plasma of mice and human patients in septic shock. Of interest, the sepsis-induced changes in cytokines were abrogated in mice deficient in functionally invariant natural killer T cells. Mice deficient in IL-13 - producing cells, including ILC2s, had a survival advantage after sepsis along with decreased morphologic evidence of tissue injury and reduced IL-10 levels in the peritoneal fluid. Administration of a suppressor of tumorigenicity 2 (IL-33R) receptor-blocking antibody led to a transient survival advantage. Taken together, these findings suggest that ILC2s may play an unappreciated role in mediating the inflammatory response in both mice and humans; further, modulating ILC2 response in vivo may allow development of immunomodulatory strategies directed against sepsis. (Am J Pathol 2018, 188: 2097-2108; https://doi.org/10.1016/j.ajpath.2018.05.009)
\end{abstract}

Sepsis is the life-threatening end-organ dysfunction that results from a dysregulated host response to an infection. ${ }^{1}$ Sepsis remains a major public health concern and leading cause of death. ${ }^{1-3}$ Sepsis is a syndrome characterized by an interplay of host proinflammatory and anti-inflammatory cell types and molecular processes, which leads to severe dysregulation of the inflammatory network. ${ }^{4}$ Traditionally, focus has been placed on an initial hyperinflammatory/proinflammatory phase, followed by a prolonged period of immunosuppression. $^{5-7}$ However, recent failures in drug trials that targeted this response argue for an alternative approach to understanding immune dysfunction associated with sepsis, whereby proinflammatory and anti-inflammatory processes occur simultaneously after initial septic insult. ${ }^{8-10}$

Previous research has shed insight into regulatory T-cell populations, including $\gamma \delta \mathrm{T}$ cells and invariant natural killer
$\mathrm{T}$ (iNKT) cells, as being critical mediators of both innate and adaptive immune responses. ${ }^{11,12}$ These unconventional T-cell subsets may directly or indirectly contribute to the development of immune dysfunction observed in sepsis, because they not only rapidly respond to environmental or infectious stimuli but also secrete an array of cytokines that can contribute to the development of memory cell phenotypes. Innate lymphoid cells (ILCs) are one of these groups of cells that have garnered much attention recently, because they can also cross the bridge between the innate and

Supported by NIH/National Institute of General Medical Sciences grants R01 GM046354-20 (A.A.), R35 GM118097 (A.A.), T32 GM065085 (N.A.H.), and K08-GM110495 (D.S.H.), and Armand D. Versaci Research Scholar in Surgical Sciences Fellowship awards (T.T.C. and E.A.F.).

Disclosures: None declared. 
adaptive immune systems. These cells derive from a common lymphoid precursor but lack acquired antigen receptors and do not undergo antigenic selection or expansion on stimulation. They can respond rapidly to signals from pathogens or damaged tissues or both by their expression of pathogen recognition receptors, which leads to the secretion of a variety of cytokines that influence the type of immune response arising at the site of infection/injury. ${ }^{13,14}$ ILCs can be categorized into three subgroups according to their secreted cytokines. ${ }^{15}$ Among these, group 2 ILCs (ILC2s) are characterized by their activation by innate immune response regulatory cytokines, including IL-25, IL-33, and thymic stromal lymphopoietin, as well as their production of predominantly $\mathrm{T}$ helper 2 (Th2)-type cytokines, including IL-5, IL-9, and IL-13. ${ }^{16-18}$

In humans, ILC2s are often associated with mucosal barrier surfaces in which they appear to have an important role in regulating both innate and adaptive immune responses to invading pathogens. ILC2s are implicated not only in diseases of the airways (including allergic lung disease, chronic rhinosinusitis, asthma, idiopathic pulmonary fibrosis) but also in diseases of the skin such as atopic dermatitis. ${ }^{19-21}$ However, recent evidence in the literature suggests that ILC2s may be present in other anatomic locations and may be implicated in certain diseases driven by Th2-type immune response or the associated upstream regulatory cytokines, namely IL-25, IL-33, and thymic stromal lymphopoietin.

Our previous work that used an animal model of sepsis demonstrated a shift away from Th1 toward a Th2 response in polymicrobial sepsis, which was posited to contribute to the immunosuppression observed in septic immune dysfunction. ${ }^{22}$ These findings give rise to a reasonable hypothesis that ILC2s may contribute to the development of septic immune dysfunction. However, despite their association with Th2-type cytokines, the potential role of ILC2s in acute polymicrobial sepsis/septic shock in mice and humans has not been elucidated to this date. Inasmuch, we set out to test the hypothesis that ILC2s are the key mediators of immune dysfunction associated with sepsis by directly or indirectly influencing the cytokine milieu present at the site of infection; thus, modulating ILC2 response in vivo should lead to changes in sepsis outcome.

\section{Materials and Methods}

\section{Animals and Sepsis Model}

Male CB6F1/J mice 6 to 10 weeks of age weighing 20 to 25 $\mathrm{g}$ (The Jackson Laboratories, Bar Harbor, ME) were used in all experiments other than those when either mice deficient in IL-13-producing cells (ILC2-deficient mice) and their background controls or $\mathrm{C} 57 \mathrm{Bl} / 6-\mathrm{J} \alpha 18^{-/-}(\mathrm{J} \alpha 18-/-$; iNKT-deficient mice; a gift from Dr. Masaru Taniguchi, RIKEN Research Center for Allergy and Immunology, Kanagawa, Japan) were examined. ${ }^{23}$ A cecal ligation and puncture (CLP) model, adopted from a protocol previously described by Baker et al, ${ }^{24}$ was performed to induce polymicrobial sepsis in mice. Briefly, a midline laparotomy was performed under general anesthesia to expose the cecum, which was ligated with a 3-0 silk tie approximately $1 \mathrm{~cm}$ from the tip. This ligated portion of the cecum was then punctured twice with a 22-gauge needle: once near the tip and once near the site of ligation. The ligated cecum was placed back into the abdomen, and the abdomen was closed with a 6-0 nylon suture. Resuscitative fluids were administered subcutaneously at the conclusion of CLP, and no antibiotics were administered.

From our prior experiences, a single time point, 24 hours after CLP, was chosen to harvest tissues and fluid samples from mice for analysis. Mortality in this CLP model typically occurred between 24 and 48 hours after the septic insult, thereby avoiding any potential selection bias incurred by choosing a later time point. Sham surgery was performed to control for the effects of general anesthesia and laparotomy on desired outcomes.

All research protocols were approved by the Institutional Animal Care and Use Committee at Rhode Island Hospital (AWC 0040-16), and all experiments were performed in accordance with the Animal Welfare Act (Laboratory Animal Welfare Act of 1966, P.L. 89-544) and NIH guidelines. $^{25}$

\section{Human Participants}

Blood samples were collected from patients admitted to intensive care units at our institution. Patients with sepsis, severe sepsis, or septic shock were identified by using the criteria previously described. ${ }^{1,26}$ Briefly, patients met systemic inflammatory response syndrome (SIRS) criteria if two or more of the following were present: abnormal body temperature $\left(<96.8^{\circ} \mathrm{F}\right.$ or $\left.>100.4^{\circ} \mathrm{F}\right)$, elevated heart rate ( $>90$ beats $/ \mathrm{min}$ ), abnormal respiratory rate ( $>20$ breaths/ min), or blood gas (partial pressure of carbon dioxide in arterial blood $<32 \mathrm{mmHg}$ ), and abnormal white blood cell count $\left(<4000 / \mathrm{mm}^{3}\right.$ or $>12,000 / \mathrm{mm}^{3}$, or $10 \%$ bands $)$. Sepsis has been historically defined as SIRS in the setting of an infectious process. Severe sepsis has been defined as sepsis with resultant organ dysfunction. Septic shock is defined as severe sepsis combined with refractory hypotension despite the administration of resuscitative intravenous fluids.

Patients were divided into two groups: sepsis and nonsepsis. The sepsis cohort included patients who showed evidence of organ dysfunction or refractory hypotension or both in the setting of an identified infectious process. The nonsepsis cohort included patients who met SIRS criteria. No significant differences were found in age and sex between patients who were included in these two groups.

All patients or legally authorized representatives signed an informed consent before the blood samples were collected. The institutional review board at our institution 
approved this research protocol (IRB Project 515666-10; CMTT 4130-13) and granted permission to analyze the patients' samples as part of this research study.

\section{Isolation and Preparation of Cells from Mice}

Because the liver and the spleen play key roles in the immune response and may be important reservoirs of regulatory cells involved in the septic inflammatory response, the liver nonparenchymal cells (NPCs) and the splenocytes were harvested to investigate potential changes in the number and percentage of ILC2s. Cells from lamina propria (LP) of the small intestines and cells or fluids from the peritoneal cavity, the site of infection in our animal model, were also harvested.

Immune cells were isolated from the LP cells (LPCs) of the murine small intestine with the use of a dissociation kit according to the methods described by the manufacturer (Miltenyi Biotec Inc., San Diego, CA). Liver NPCs were isolated according to a protocol previously outlined by Wesche-Soldato et al. ${ }^{27}$ The liver was perfused with collagenase and heat-inactivated fetal bovine serum in Hank's balanced salt solution (Thermo Fisher Scientific, Waltham, MA) and dissected into small pieces by using scissors. After digestion at $37^{\circ} \mathrm{C}$, hepatocytes were removed by slow centrifugation $(30 \times g$ for 10 minutes). The remaining cells in the supernatant were enriched with 30\% Histodenz solution (Sigma-Aldrich, St. Louis, MO) and separated by high-speed centrifugation $(1650 \times g$ for 30 minutes). Splenocytes were isolated according to a protocol previously described by Meldrum et al. ${ }^{28}$ The spleen was harvested and gently ground between frosted microscope slides. The erythrocytes were lyzed by hypotonic shock. Mouse peritoneum was lavaged with phosphate-buffered saline to harvest peritoneal cells.

\section{Identification of Murine ILC2s by Flow Cytometry}

The isolated cells of the small intestine LP, liver NPCs, splenocytes, and peritoneal cells were first counted by using light microscopy. Flow cytometric staining antibody panel and sample gating strategies used to identify ILC2s are as described by Halim et al. ${ }^{29}$ Cells were stained with propidium iodide (PI) to exclude nonviable cells and with antilineage antibodies, including anti-CD3e, CD19, NK1.1, Gr-1, Ter119, CD11b antibodies, anti-CD45, anti-CD127, anti-CD117, anti-CD25, anti-CCR6, anti-Sca-1 (Miltenyi Biotec Inc.), and anti-IL33R $\alpha$ (ST2) (BioLegend, San Diego, CA) antibodies, as well as with the appropriate isotope control antibodies (Miltenyi Biotec Inc.).

Samples were then read with MACSQuant Analyzer 10 and analyzed with FlowJo software version 10 (TreeStar Inc., Ashland, OR). Cells were first gated for viability $\left(\mathrm{PI}^{-}\right)$, small size/nongranularity (forward scatter ${ }^{\text {low }}$ side scatter ${ }^{\text {low }}$ ), and leukocytes $\left(\mathrm{CD} 45^{+}\right)$. ILC2s from the small intestine LP, liver NPCs, splenocytes, and the peritoneal cavity were then identified by Lineage ${ }^{-} \mathrm{CD} 127^{+} \mathrm{CD} 25^{+}$Sca$1^{+} \mathrm{CD} 117^{- \text {int }} \mathrm{T} 1 / \mathrm{ST}^{+} \mathrm{CCR}^{-}$. Gating strategies used for flow cytometric experiments are described in Supplemental Figure S1.

\section{Measurement of Cytokine and Alanine Aminotransferase Levels}

IL-1 $\beta$, IL-6, IL-10, IL-13, IL-25, IL-33, and tumor necrosis factor (TNF)- $\alpha$ levels present in the mouse plasma and in the peritoneal fluid were determined by using enzymelinked immunosorbent assay kits for IL-1 $\beta$, IL-6 (R\&D Systems, Minneapolis, MN), IL-10 (BioLegend), and IL-13, IL-25, and IL-33 (Affymetrix, Santa Clara, CA) according to the methods described by the manufacturers. IL-33 level present in the human plasma was determined with an enzyme-linked immunosorbent assay kit for human IL-33 (R\&D Systems). Plasma alanine aminotransferase levels were determined according to the methods described by the manufacturer's kit (Sigma-Aldrich).

\section{Experimental Mice}

Mice deficient in IL-13-producing cells, including ILC2s, have been previously described by Price et al. ${ }^{30}$ Briefly, an IL-13 reporter mouse strain with yellow fluorescent protein (YFP)-enhanced transcript with Cre recombinase at the IL13

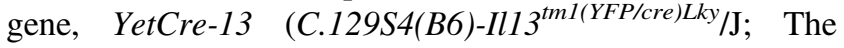
Jackson Laboratories) was crossed with a ROSA-flox-Stopdiphtheria toxin $\alpha$ mouse strain, ROSA-DTA (B6.129P2-

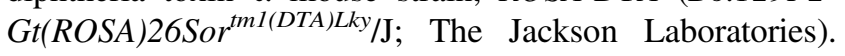
The hybrid offspring of this cross do not have IL-13producing cells, because activation of IL-13 transcription produces YFP-Cre fusion protein, which targets the floxstop cassettes and leads to generation of diphtheria toxin $\alpha$ (DTA), which then selectively ablates IL-13-producing cells. Cells, including the Th2 cells, iNKT cells, mast cells, and basophils, are known to produce IL-13. However, as Price et $\mathrm{al}^{30}$ reported, lineage-negative cells are the main innate IL-13-expressing cells, especially during infection and stimulation with inflammatory cytokines such as IL-25. Therefore, by removing IL-13-producing cells with the use of this technique, the experimental mouse strain was essentially deficient in the ILC2s. The genotypes of both parental mouse strains and offspring were confirmed by tail snipping and PCR assays with the use of appropriate primers (Table 1) (The Jackson Laboratories). CB6F1/J mice were used as controls.

\section{In Vivo Modulation of ILC2s with IL-33R $\alpha$ (ST2) Receptor-Blocking Antibody}

$\mathrm{CB} 6 \mathrm{~F} 1 / \mathrm{J}$ mice were treated with two administrations of low endotoxin, azide-free anti-mouse IL-33R $\alpha$ (ST2) receptor-blocking antibody or IgG isotope control antibody by tail vein injection $(50 \mu \mathrm{g}$ per mouse each dose $),{ }^{17}$ the first 
Table 1 PCR Primer Sets Used for Genotyping of Both Parental Mouse Strains, YetCre-13 (C.129S4(B6)-Il13 ${ }^{\text {tm1(YFP/cre)Lky } / J}$ and

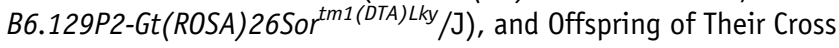

\begin{tabular}{|c|c|c|}
\hline Allele & Directions & Sequences \\
\hline \multicolumn{3}{|l|}{ Gt(ROSA)26Sor ${ }^{\text {tm1(DTA)Lky }}$} \\
\hline Wild-type (13840) & Forward & $\begin{array}{c}5^{\prime} \text {-CCAAAGTCGCTCTG- } \\
\text { AGTTGTTATC- } 3^{\prime}\end{array}$ \\
\hline Wild-type (13841) & Reverse & $\begin{array}{l}5^{\prime} \text {-GAGCGGGAGAAATG- } \\
\text { GATATG- } 3^{\prime}\end{array}$ \\
\hline Mutant (12211) & Forward & $\begin{array}{l}5^{\prime} \text {-CGACCTGCAGGTC- } \\
\text { CTCG-3' }\end{array}$ \\
\hline Mutant (8824) & Reverse & $\begin{array}{c}5^{\prime} \text {-CTCGAGTTTGTCCA- } \\
\text { ATTATGTCAC-3' }\end{array}$ \\
\hline \multicolumn{3}{|l|}{$\mathrm{Il} 13^{\mathrm{tm} 1(\mathrm{YFP} / \mathrm{cre}) \mathrm{Lky}}$} \\
\hline Wild-type (14638) & Forward & $\begin{array}{l}5^{\prime}-\text { TGCTGAATGCCAAC- } \\
\text { TGTTCT- } 3^{\prime}\end{array}$ \\
\hline Wild-type (14639) & Reverse & $\begin{array}{l}5^{\prime}-\text { СТТССТССТСААСС- } \\
\text { СТССТС- } 3^{\prime}\end{array}$ \\
\hline Transgene (oIMR9266) & Forward & $\begin{array}{c}5^{\prime}-\text { AGATGCCAGGACAT- } \\
\text { CAGGAACCTG- } 3^{\prime}\end{array}$ \\
\hline Transgene (oIMR9267) & Reverse & $\begin{array}{c}5^{\prime}-\text { ATCAGCCACACCAG- } \\
\text { ACACAGAGATC- } 3^{\prime}\end{array}$ \\
\hline
\end{tabular}

PCR primer sets used for genotyping and both parental mouse strains were obtained from The Jackson Laboratories.

simultaneously with CLP or sham surgery and the second at 8 hours after surgery (clone DIH4; BioLegend). Tissues and fluids were harvested 24 hours after CLP or sham surgery to investigate the effects of changing ILC2 response in vivo.

\section{Survival Study}

$\mathrm{CB} 6 \mathrm{~F} 1 / \mathrm{J}$ mice were treated with either IgG isotope or antimouse IL-33R $\mu$ (ST2) receptor-blocking antibody and underwent CLP. Their survival was monitored for 14 days. The mice were allowed food and water ad libitum during this postoperative period.

\section{Histologic Examination}

The tissues were fixed in $10 \%$ formalin solution for 24 hours and embedded in paraffin blocks for sectioning. The histologic slides of the liver and the terminal ileum were prepared and stained with hematoxylin and eosin for the light microscopic examination. With the use of $\times 100$ magnification, the slides were then provided to a pathologist (C.-S.C.) in a specimen-identity-blinded fashion and examined for morphologic integrity as well as any evidence of tissue viability or necrosis or both.

\section{Bacterial Burden}

Whole blood (diluted to 1:10 in sterile phosphate-buffered saline) and peritoneal fluids (diluted to $1: 100$ in sterile phosphate-buffered saline) were collected from mice. These samples were plated on sheep's blood agar and incubated for 24 hours at $37^{\circ} \mathrm{C}$. The plates were then visually inspected, and total numbers of bacterial colonyforming units $(\mathrm{cfu})$ were determined per milliliter of samples.

\section{Statistical Analysis}

SigmaPlot version 11 (Systat Software, Inc., San Jose, CA) was used for all statistical analyses, and data were presented as means \pm SEM. The $t$-test was used to compare two sets of continuous data, and modified analysis of variance was used to compare multiple sets of continuous data from flow cytometry and enzyme-linked immunosorbent assay for various cytokine levels. Kaplan-Meier log-rank survival analysis was performed for survival studies. Differences were considered to be significant at $P<0.05$.

\section{Results}

ILC2s Increase in Number and Percentage at the Site of Infection

ILC2s were identified at 4 and 24 hours after sham or CLP surgery by flow cytometry (Figure 1A and Supplemental Figure S2A). In the small intestine LPCs, sham protocol and CLP induced a substantial rise in LPC number from 4 to 24 hours after insult; however, at 24 hours after CLP resulted there was an almost twofold further increase in the percentage of ILC2s $(0.60 \%$ versus $0.33 \% ; P=0.02)$ and in the number $(108,353$ versus 62,027 cells; $P=0.005)$ of ILC2s compared with sham surgery (Figure 1B and Supplemental Figure S2B).

Alternatively, although there was a rise in the sham surgery mouse liver ILC2s percentage number going from 4 to 24 hours, there was a marked ILC2s decrease in both percentage and number in the liver NPCs after CLP not only versus sham surgery at 24 hours but also compared with 4 hours (Figure 1C and Supplemental Figure S2, C and D). Such decline in the number and percentage of ILC2s was not due to a global loss of the liver cells resulting from septic shock, because the total yield of liver NPCs did not change from sham surgery or CLP livers. In the peritoneal cavity, ILC2s did not change in percentage $(0.18 \%$ versus $0.13 \% ; P=0.37)$ but increased in number $(29,994$ versus 15,464 cells; $P=0.01$ ) by almost twofold after CLP compared with sham surgery (Figure 1D). This observation may be a result of the influx of other immune cells into the peritoneal cavity, because the total yield of peritoneal cells through lavage was significantly higher in CLP mice than in sham protocol mice. ${ }^{32,33}$ CLP resulted in a significant decrease in the number of ILC2s in the splenocytes $(17,911$ versus 81,060 cells; $P=0.024$ ), and there was a general trend toward decrease in percentage of ILC2s as well (Figure 1E).

From a temporal perspective, although at the earlier time point of 4 hours after CLP or sham protocol no 
A

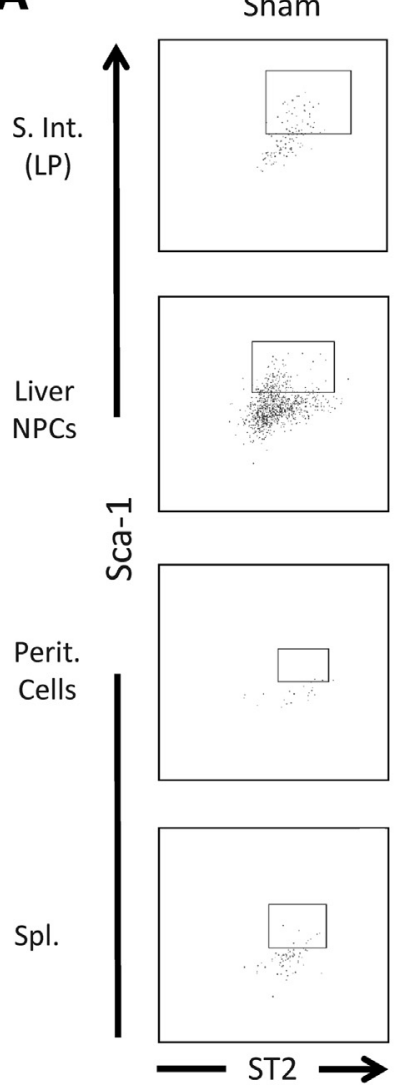

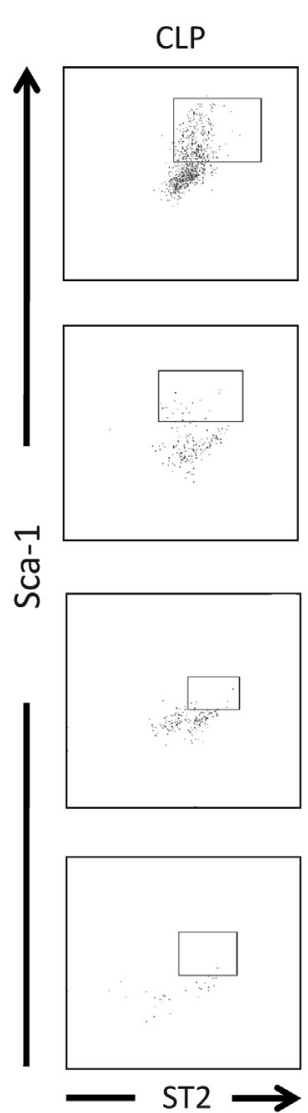

B

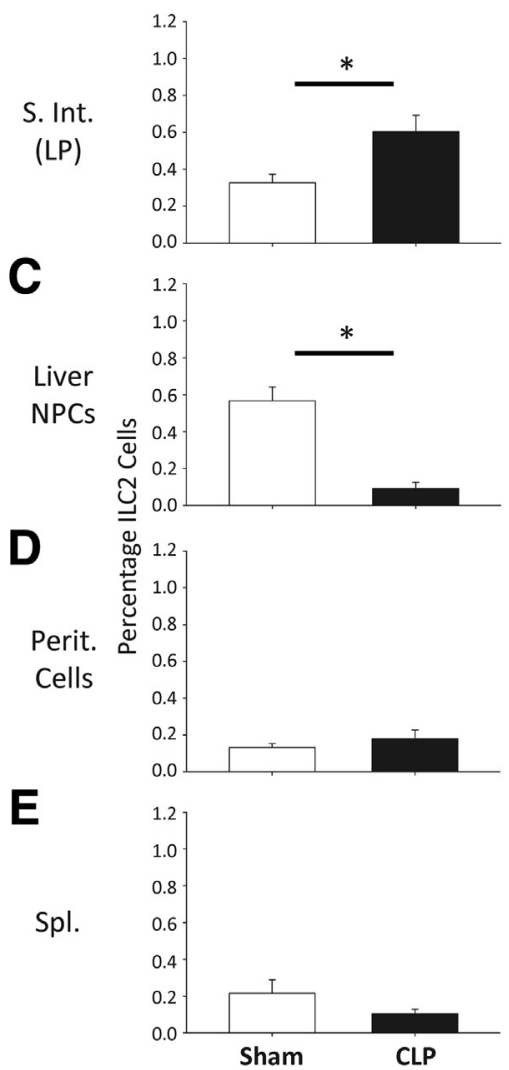

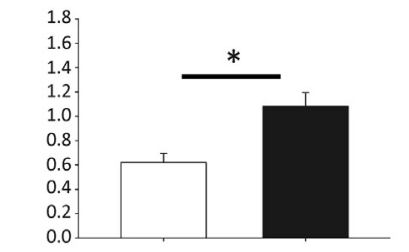
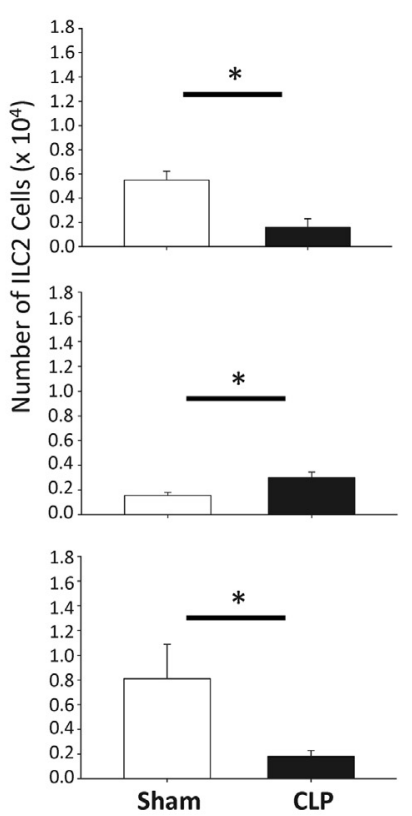

Figure 1 Changes in the number and percentage of group 2 innate lymphoid cells (ILC2s) among the lamina propria (LP) cells (LPCS) of the small intestine (s. int.), the nonparenchymal cells (NPCs) of the liver, the peritoneal (perit.) cells, and the splenocytes (Spl.). A: Flow cytometric analysis showing Lineage $^{-}$/propidium iodide (PI) ${ }^{-}$CD127 $7^{+}$CD25 $5^{+}$CD117 ${ }^{-}$(LPCs and liver NPCs) and Lineage ${ }^{-} / \mathrm{PI}^{-} \mathrm{CD} 127^{+} \mathrm{CD} 117^{-}$(peritoneal cells and splenocytes) cells that were double positive for Sca-1 and ST2 (boxed areas denote ILC2s) 24 hours after sham or cecal ligation and puncture (CLP) surgery. B-E: ILC2s changed in their number and proportion at different tissue/fluid compartments after CLP surgery. Data are expressed as means \pm SEM. $n=7$ to 12 mice for all groups. $* P<0.05$ (t-test).

significant differences were detected in the number or percentage of ILC2s in the LP of the small intestine or the liver NPCs, the percentage and numbers rose over those first 20 hours in all of the groups with the exception of the liver (where they further declined) (Supplemental Figure S2). These data suggested that, although general anesthesia and laparotomy had a modest effect on the ILC2 levels, these were still significantly affected by the presence of CLP.

\section{Changes in ILC2 Effector and Activating Cytokines}

An increased level of IL-13 was present in the peritoneal fluid after CLP (41.7 versus $7.4 \mathrm{pg} / \mathrm{mL} ; P=0.001$ ), but no changes in circulating IL-13 level in the plasma were noted ( 0.43 versus $1.60 \mathrm{pg} / \mathrm{mL} ; P=0.30$ ) (Figure 2A). Although IL-13 was known to be produced by several cell types, including T cells, NK cells, mast cells, eosinophils, basophils, and dendritic cells, ILC2s could be active locally at the site of infection and may have contributed to the increased production of IL-13 seen in the peritoneal cavity.
A significantly increased level of IL-33 was found in both the peritoneal fluid $(9.3$ versus $0.36 \mathrm{pg} / \mathrm{mL} ; P=0.002)$ and in the plasma (105.1 versus $43.3 \mathrm{pg} / \mathrm{mL} ; P=0.01)$ after CLP (Figure 2B). However, no significant difference was noted in IL-25 level in either the peritoneal fluid (144.4 versus $86.4 \mathrm{pg} / \mathrm{mL} ; P=0.42$ ) or in the plasma ( 52.5 versus $166.4 \mathrm{pg} / \mathrm{mL} ; P=0.2$ ) in CLP mice (Figure 2C). In addition, a noted increase was found in the plasma alanine aminotransferase levels of the CLP mice compared with sham surgery mice at 24 hours after insult ( 8.2 versus 4.7 IU/L; $P<0.04)$ (Supplemental Figure S3).

\section{Patients with Sepsis versus Nonsepsis}

To investigate whether these findings translated to humans, critically ill patients in the intensive care unit with either sepsis/septic shock or with SIRS (sterile inflammation) or nonsepsis were enrolled. Patients were matched with respect to age and sex. Five of the eight septic patients had an abdominal source of sepsis, and the other three patients had pneumonia as the source of sepsis. Patients with sepsis or septic shock had a higher level of circulating IL-33 in their 

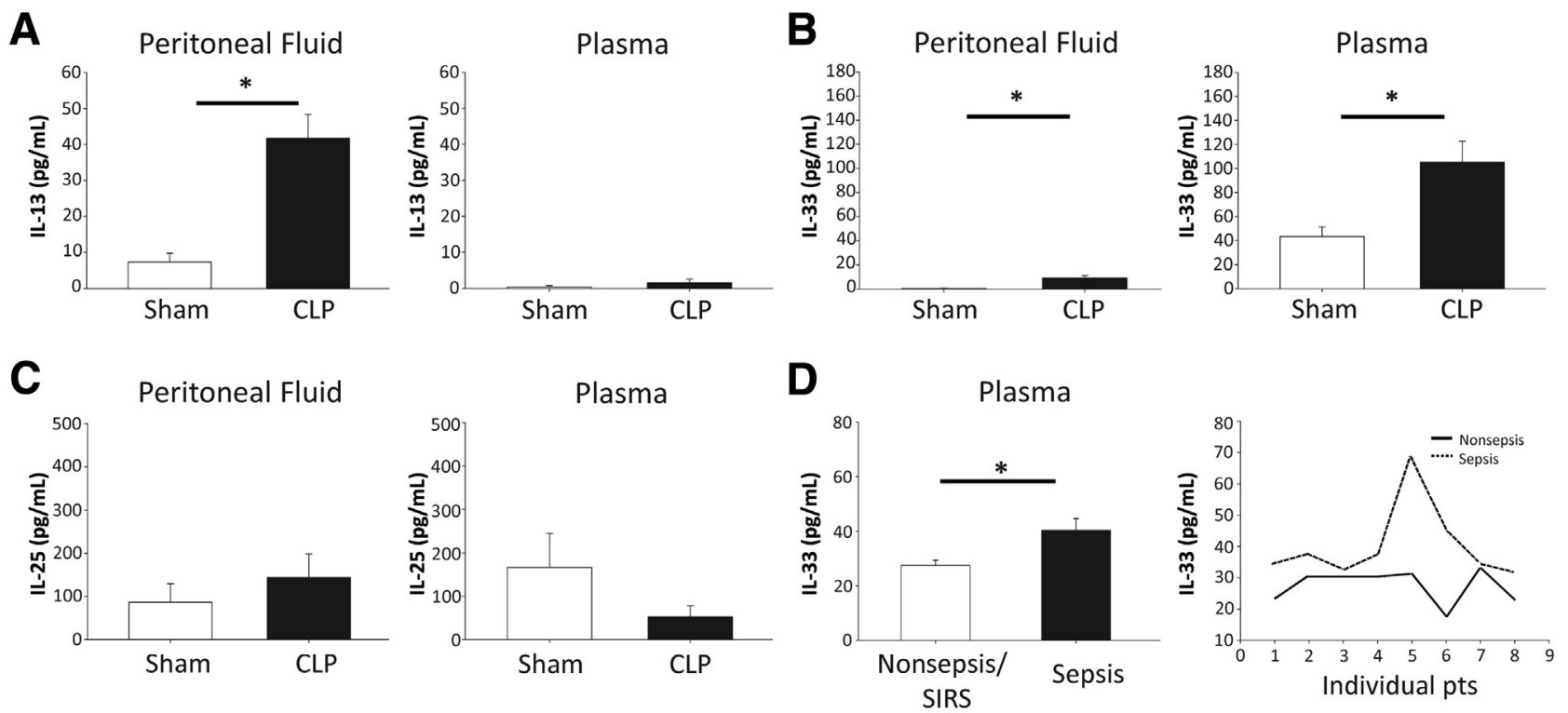

Figure 2 Changes in group 2 innate lymphoid cells (ILC2s)-regulating cytokine levels in the peritoneal fluid and the plasma after cecal ligation and puncture (CLP) compared with sham surgery. A: IL-13 level was increased in the peritoneal fluid, but no significant level of circulating IL-13 was detected in the plasma. B: IL-33 was increased in both the peritoneal fluid and in the plasma after CLP surgery. C: However, no significant change in IL-25 level was noted in the peritoneal fluid and in the plasma. D: In humans, patients (pts) admitted to intensive care units with sepsis or septic shock have a higher level of circulating IL-33 in their plasma. Data are expressed as means \pm SEM. Individual values were plotted separately. $n=5$ to 7 mice per group (A); $n=5$ to 6 mice per group (B); $n=6$ mice per group (C); $n=8$ patients per group (D). ${ }^{*} P<0.05$ (t-test). SIRS, systemic inflammatory response syndrome.

plasma than the nonseptic patients $(40.3$ versus $27.5 \mathrm{pg} / \mathrm{mL}$; $P=0.02$ ) (Figure 2D).

\section{Experimental Mice Have a Survival Advantage}

Experimental mice deficient in IL-13-producing cells and, therefore, ILC2s were generated with a Cre/lox breeding scheme. ${ }^{30}$ To confirm that this breeding scheme successfully ablated ILC2s, the cells from the small intestine LPCs, because this appeared to be one of the most abundant sources of ILC2s based on previous findings, were analyzed (Figure 1A). ${ }^{31}$ There was an almost complete elimination of Lineage ${ }^{-} / \mathrm{PI}^{-} \mathrm{CD} 127^{+} \mathrm{CD} 25^{+} \mathrm{CD} 117^{-}$cells that were double positive for Sca-1 and ST2 in these mice (Figure 3A). A survival study revealed an advantage in experimental mice that was detectable as early as 48 hours and remained persistent up to 14 days after initial septic insult $(n=19$ to 20 mice per group; $P=0.03$ ) (Figure 3B). In line with this observation, experimental mice showed a significantly improved ability to clear bacteria from the peritoneal cavity after CLP $(267,667$ versus $965,000 \mathrm{cfu} / \mathrm{mL} ; P=0.02$ ) (Figure $3 \mathrm{C}$ ). However, despite there being a general trend toward a decrease in the amount of bacteria present in blood, no statistically significant difference was observed between experimental and control mice after CLP $(17,020$ versus $4075 \mathrm{cfu} / \mathrm{mL}$; $P=0.15$ ) (Figure 3C).

To investigate the extent to which ablation of ILC2s may be playing a role in altering the cytokine milieu within the peritoneal cavity in sepsis, TNF- $\alpha$, IL-6, IL-1 $\beta$, and IL-10 levels in the peritoneal fluid samples were determined. As in control mice, experimental mice demonstrated increased levels of TNF- $\alpha$ and IL- 6 after CLP. However, these mice failed to show an increase in IL-1 $\beta$ and IL-10 levels. Most strikingly, there was a reduction in IL-10 levels after CLP in experimental mice (96 versus $1289 \mathrm{pg} / \mathrm{mL} ; n=6$ mice per group; $P<0.001$ ) (Figure 3D).

To assess the effects of ILC2s on structure and function at the organ level, the liver and the terminal ileum were examined for evidence of morphologic tissue damage by using light microscopy. In the liver of control mice, CLP was associated with hepatocyte hypertrophy, infiltration of inflammatory cells, venous congestion, dilation, and destruction of portal triad integrity compared with sham protocol mice (Figure 4, A and B). In experimental mice, the CLP liver retained a considerable integrity throughout and exhibited only mild changes associated with liver injury such as venous congestion (Figure 4, C and D). In the terminal ileum of control mice, CLP was associated with shortening of the villi, goblet cell proliferation, and microhemorrhage near the basement membrane compared with sham protocol mice (Figure 4, E and F). Experimental mice demonstrated a restoration of villi length, the lack of microhemorrhage, normal goblet cell density, and almost identical histologic features compared with sham protocol mice (Figure 4, G and H).

\section{iNKT Cells May Play a Regulatory Role}

Prior studies indicated that iNKT cells not only respond to antigen release as a component of tissue damage or infectious agents encountered in the septic animal, and do 

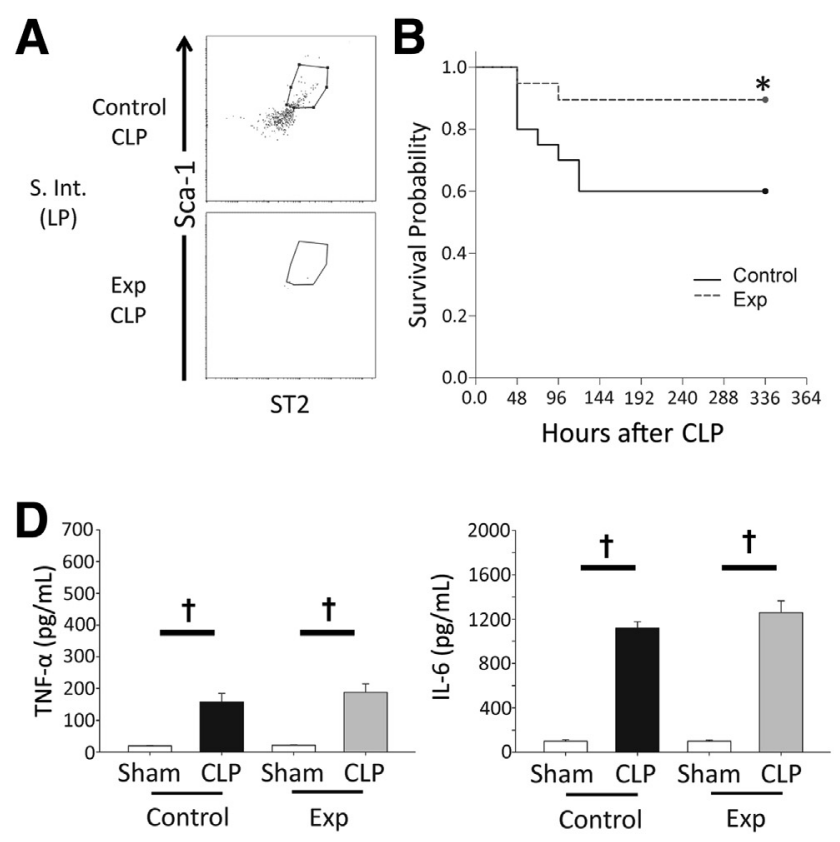
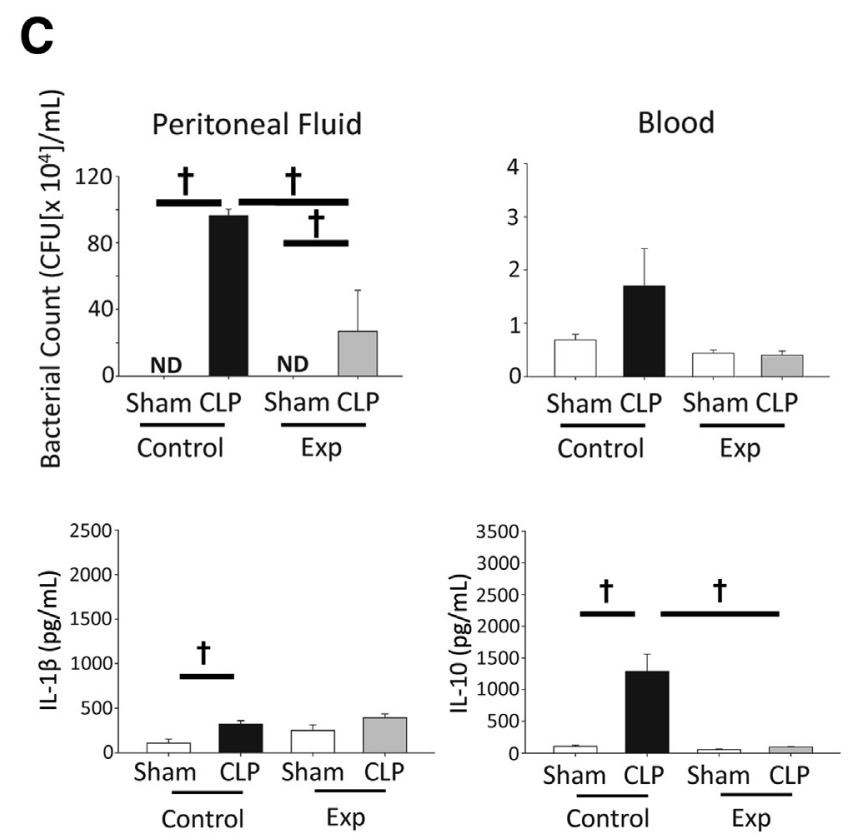

Figure 3 Immunophenotyping and survival of group 2 innate lymphoid cell (ILC2)-deficient mice after cecal ligation and puncture (CLP) surgery. A: Flow cytometric data showing the elimination of lineage ${ }^{-}$/propidium iodide (PI) ${ }^{-}$CD127 $7^{+}$CD25 ${ }^{+}$CD117 $7^{-}$cells that are double positive for Sca-1 and ST2 in the lamina propria (LP) of the small intestine (s. int.) after CLP surgery. B: Survival study demonstrating a persistent survival advantage for mice deficient in ILC2s after CLP surgery. C: Bacterial burden assay showing a significantly lower bacterial count in the peritoneal fluid after CLP surgery in ILC2-deficient mice than in control mice, but no significant difference was found in the whole blood. D: Changes in tumor necrosis factor (TNF)- $\alpha$, IL-6, IL-1 $\beta$, and IL-10 levels were shown in the peritoneal fluid after CLP surgery in control (CB6F1/J mice) and ILC2-deficient mice. Data are expressed as means \pm SEM. $n=19$ to 20 mice per group (B); $n=3$ to 5 mice per group (C); $n=6$ to 8 mice per group (D). ${ }^{*} P<0.05$ (log-rank Kaplan-Meir survival analysis); ${ }^{*}<0.05$ (one-way analysis of variance). Exp, experimental; ND, not detected.

this in part through their interactions with other leukocytes, but also markedly alter the response to septic challenge. ${ }^{11,33,34}$ The increase in IL-33 level in the peritoneal fluid was not observed in $J \alpha 18^{-/-}$mice after CLP. Similarly, the increase in IL-13 level in the peritoneal fluid was not observed in $J \alpha 18^{-1-}$ mice after CLP. (Figure 5).

\section{Targeting ILC2 Response to Sepsis}

A blocking antibody was administered for the IL-33R $\alpha$ (ST2) receptor (an agent that blocks the capacity of IL-33 to activate ILC2 cells). ${ }^{35}$ A survival study that used agematched mice treated with IgG isotope or ST2 receptor-blocking antibody resulted in a transient, yet significant, survival advantage in mice treated with blocking antibody. The difference in survival was evident up to 72 hours after CLP surgery ( $n=15$ to 16 mice per group; $P=0.03$ ), but this difference in survival disappeared after 96 hours (Figure 6A).

Changes in cytokine milieu within the peritoneal cavity were next examined after administration of ST2 receptor-blocking antibody. Mice treated with $\operatorname{IgG}$ isotope antibody demonstrated increased levels of TNF- $\alpha$, IL-6, IL-1 $\beta$, and IL-10 after CLP compared with the sham protocol mice. Mice treated with ST2 receptor-blocking antibody showed attenuated increases in IL-1 $\beta$ (717 versus $2133 \mathrm{pg} / \mathrm{mL} ; P=0.006)$ and $\mathrm{IL}-10(1068$ versus $2756 \mathrm{pg} / \mathrm{mL} ; P<0.001)$ levels, whereas no significant differences were seen in the observed increases in TNF- $\alpha$ and IL-6 levels after CLP compared with isotope-treated mice. However, a significantly reduced level of IL-10 in ST2 antibody-treated mice was detected (Figure 6B).

The liver and the terminal ileum were reexamined with light microscopy. Mice treated with ST2 receptor-blocking antibody displayed structural integrity and only mild changes in the gross examination of the liver such as venous congestion (Figure 7, A-D). In the terminal ileum, the mice treated with ST2 receptor-blocking antibody failed to demonstrate restoration of villi length, a lack of microhemorrhage at the basement membrane, and normal density of goblet cells in the epithelium. Histologic features observed in mice treated with ST2 blocking-antibody after CLP were almost identical to those observed in sham mice (Figure 7, E-H).

\section{Discussion}

Much of the early discussion about sepsis and the treatment of sepsis focused on the hyperinflammatory phase of the septic immune response. Septic patients frequently display fever, tachycardia, tachypnea, and leukocytosis, which were collectively identified as SIRS. ${ }^{24}$ Proinflammatory cytokines, including TNF- $\alpha$, IL- $1 \beta$, and interferon- $\gamma$, were 

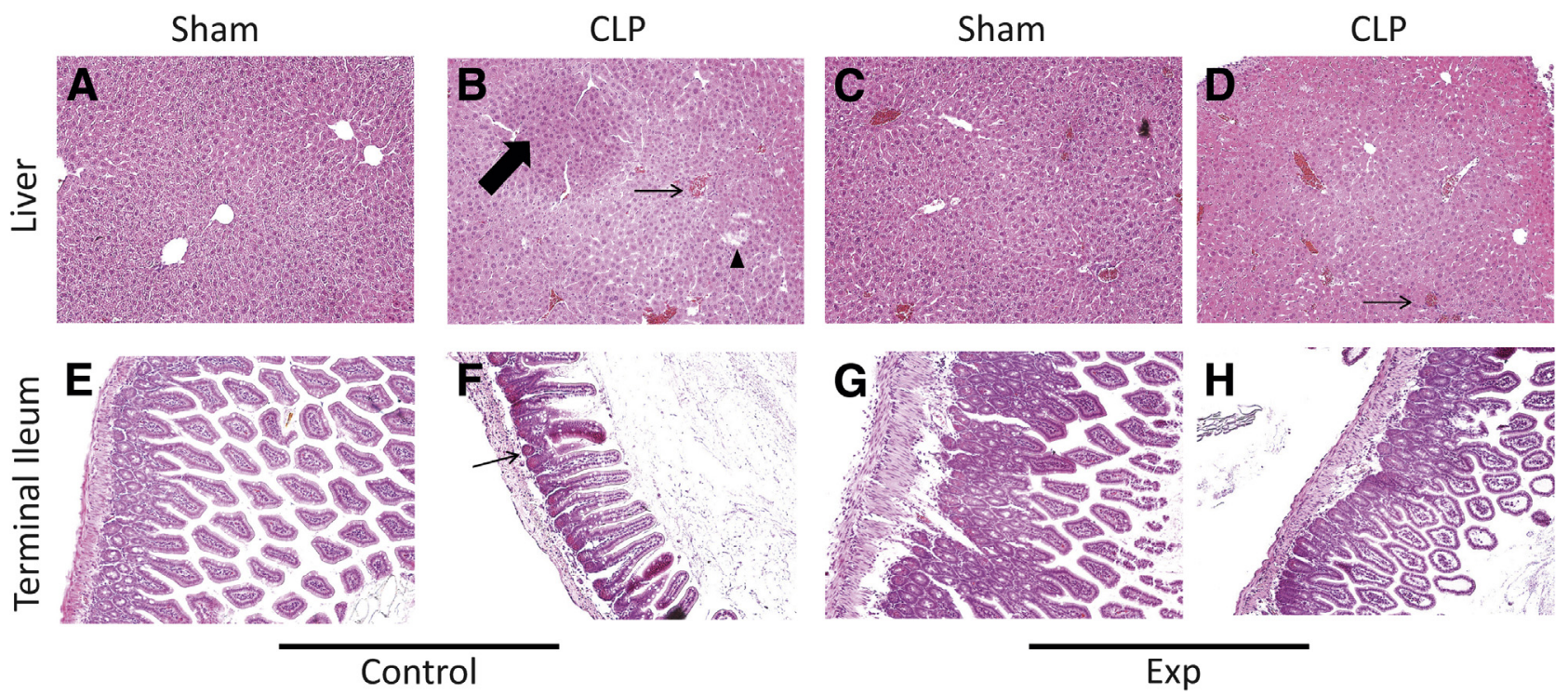

Figure 4 Hematoxylin and eosin staining of the mouse liver $(\mathbf{A}-\mathbf{D})$ and the small intestine at the terminal ileum (E-H) in control mice and group 2 innate lymphoid cell (ILC2)-deficient mice. B: In the liver of control mice, cecal ligation and puncture (CLP) was associated with evidence of venous congestion and dilation (thin arrow), hepatocyte hypertrophy, infiltration of inflammatory cells (thick arrow), and destruction of portal triad integrity (arrowhead). D: In ILC2-deficient mice, the liver maintained considerable integrity and showed only mild changes, including venous congestion and dilation (thin arrow). F: In the terminal ileum of control mice, CLP was associated with shortening of the villi, proliferation of the goblet cells, and microhemorrhage near the basement membrane (thin arrow). H: In ILC2-deficient mice, the terminal ileum maintained structural integrity and did not demonstrate proliferation of goblet cells. Original magnification, $\times 100$ (light microscopy). Control, CB6F1/J mice; Exp, experimental.

believed to be the driving factors of this inflammatory response leading to death in septic patients, because their levels were found to be closely correlated with the severity of sepsis and septic shock. ${ }^{36-38}$ However, drug therapies designed to target components of this hyperinflammatory immune response with a toll-like receptor 4 antagonist and an anti-TNF- $\alpha$ fragment antigen binding fragments, failed to reduce sepsis-related death in clinical trials. ${ }^{8,9}$ This has compelled some researchers and clinicians to start considering an alternative approach to sepsis treatment. ${ }^{39}$ Evidence for the importance of the hypoinflammatory phase of the septic immune response has always been strong, because a number of studies have shown that immunosuppression is associated with sepsis-related morbidity and death. ${ }^{6,7,40}$ However, the conventional model of sepsis progression, in which an initial predominance of hyperinflammatory response is followed by a more protracted period of immunosuppression, is in question. It is now widely accepted that both proinflammatory and anti-inflammatory responses coexist as mixed antagonist response syndrome
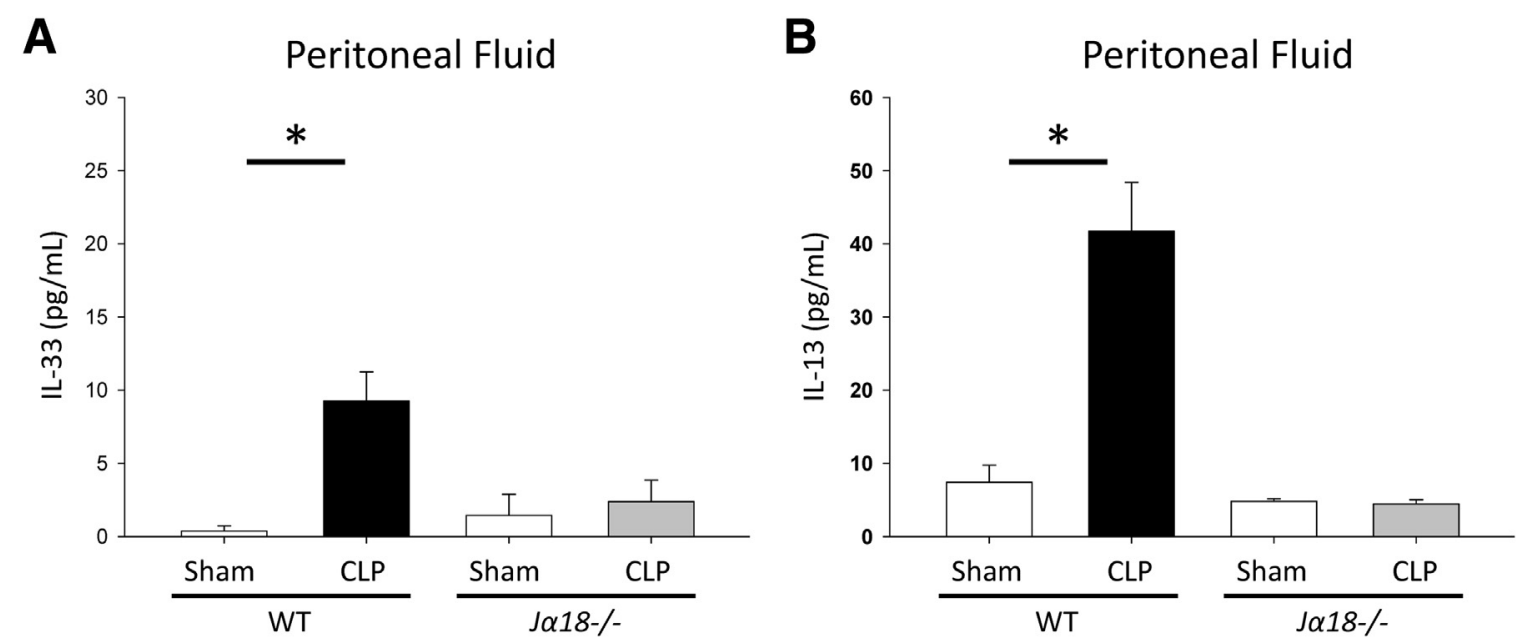

Figure 5 Changes in IL-33 and IL-13 levels after cecal ligation and puncture (CLP) surgery. A: IL-33 level was increased in the peritoneal fluid of wild-type (WT) mice after CLP, but this increase was not observed in J $\alpha 18^{-/-}$mice (invariant natural killer T cell-deficient mice) after CLP. B: IL-13 level was also increased in the peritoneal fluid of WT mice after CLP, but, similarly, this increase was not observed in Ja18 ${ }^{-/-}$mice after CLP. $n=5$ to 7 mice per group ${ }^{*} P<0.05$ (one-way analysis of variance). 
A

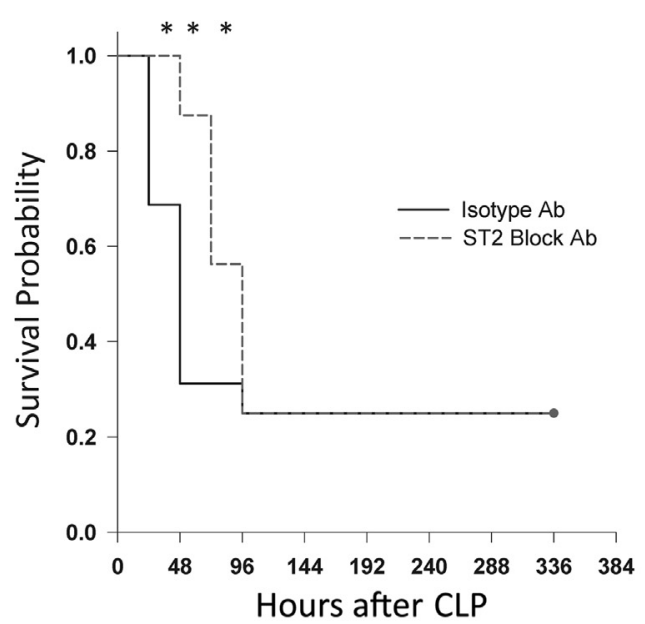

B
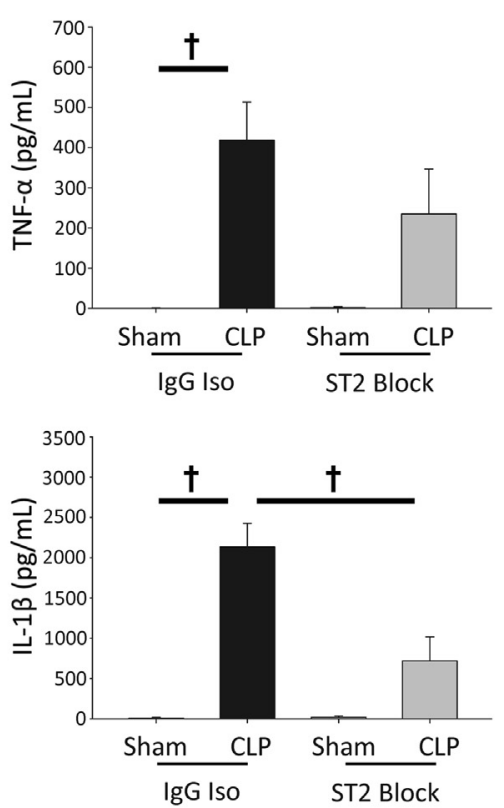

Peritoneal Fluid
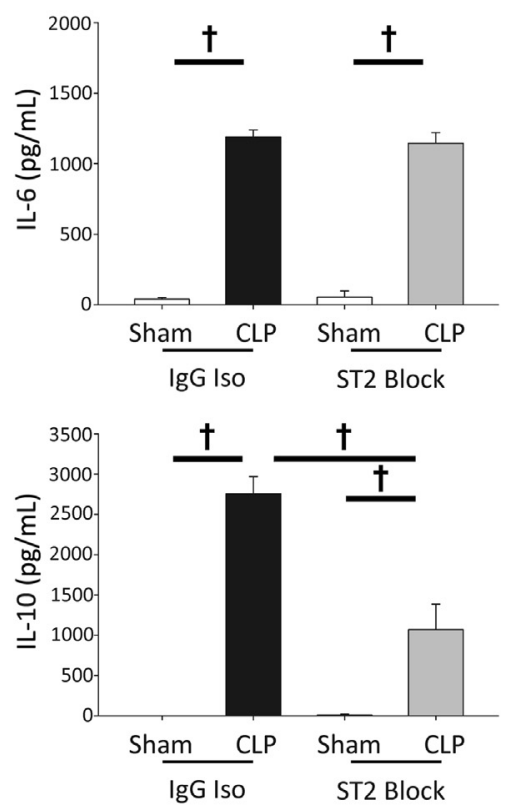

Figure 6 Immunophenotyping and survival of mice treated with ST2-blocking antibody after cecal ligation and puncture (CLP). Survival study demonstrating a transient survival advantage for mice treated with ST2-blocking antibody up to 72 hours after CLP surgery. A: This difference in survival disappeared after 96 hours. B: Changes in tumor necrosis factor (TNF)- $\alpha$, IL-6, IL-1 $\beta$, and IL-10 levels in the peritoneal fluid after CLP surgery in mice treated with IgG isotype (Iso) antibody and those treated with ST2 blocking antibody. Data are expressed as means \pm SEM. $n=15$ to 16 mice per group (A); $n=3$ to 5 mice per group (B). ${ }^{\star} P<0.05$ (log-rank Kaplan-Meir survival analysis); ${ }^{\dagger} P<0.05$ (one-way analysis of variance).

as evidenced by the production of both proinflammatory and anti-inflammatory cytokines by immune cells in early postoperative sepsis. ${ }^{22,41}$ ILC2s are a group of cells that have the unique ability to rapidly respond to the signals from damaged/infected tissues and lead to production of Th2-type cytokines, such as IL-5, IL-9, and IL-13. As such, they may have a critical role in mediating inflammatory response to sepsis.

Our findings that ILC2s are present in small numbers, but increase in number and percentage at the site of infection, imply that these cells may be recruited to the site of infection during acute septic response. Previous work suggested that another regulatory T-cell population, iNKT cells, emigrate out of the liver into the peritoneal cavity potentially by a programed cell death protein-1-mediated pathway. ${ }^{12,42}$ Because the liver is implicated as the source of the acute-phase mediator response and is frequently compromised during intraabdominal sepsis, it may be an important reservoir of regulatory cells involved in septic inflammatory response. ${ }^{43}$ The same notion of cell emigration and chemotaxis could be true for ILC2s, because our findings suggest that ILC2s decrease in both number and percentage in the liver NPCs after CLP. The impact the absence of the iNKT cells had on the ILC2 numbers of the CLP mouse in the peritoneum and/or the liver could not directly be documented. However, with the use of the iNKT cell-deficient mice, it was shown that the lack of these cells resulted in obliteration of the CLPinduced elevation of not only the ILC2 activating cytokine IL-33 but also the CLP-induced rise of the ILC2's effector molecule IL-13. Therefore, direct/indirect interaction between the iNKT cells and the ILC2s are likely. However, further research is warranted to elucidate the exact pathway and mechanism responsible for ILC2 emigration and chemotaxis.

These data support the recent observation that IL-33 plays an important role in innate-type mucosal immunity in the gut. ${ }^{44}$ As an activator of ILC2 response, endogenous IL-33 is seen at highest concentration at epithelial barrier tissues, which may suggest that IL-33 acts as an Alarmin to alert the innate immune system of tissue injury at the site of infection. ${ }^{45}$ In line with this, increased levels of IL-33 in the plasma and peritoneal fluids of septic mice, as well as increased levels of IL-33 in the plasma of septic patients in the intensive care unit, were observed. This is consistent with data previously reported in the literature and adds to the notion that IL-33 may be an important biomarker of sepsis. ${ }^{46}$ However, these findings diverge from a previous report that treating mice with IL-33 resulted in a greater influx of neutrophils into the peritoneal cavity after CLP surgery and overall improved bacterial clearance. ${ }^{47}$ These results also diverge from previous findings that treating mice with IL-33 has immunoprotective activity by inhibiting the apoptosis of $\mathrm{CD}^{+}$and $\mathrm{CD}^{+}{ }^{+} \mathrm{T}$ lymphocytes and leads to improved survival after CLP. ${ }^{48}$ There may be an expanded role for IL-33 in influencing many cell types during acute septic response, and IL-33 may, in fact, be an important element of the host defense mechanism. 

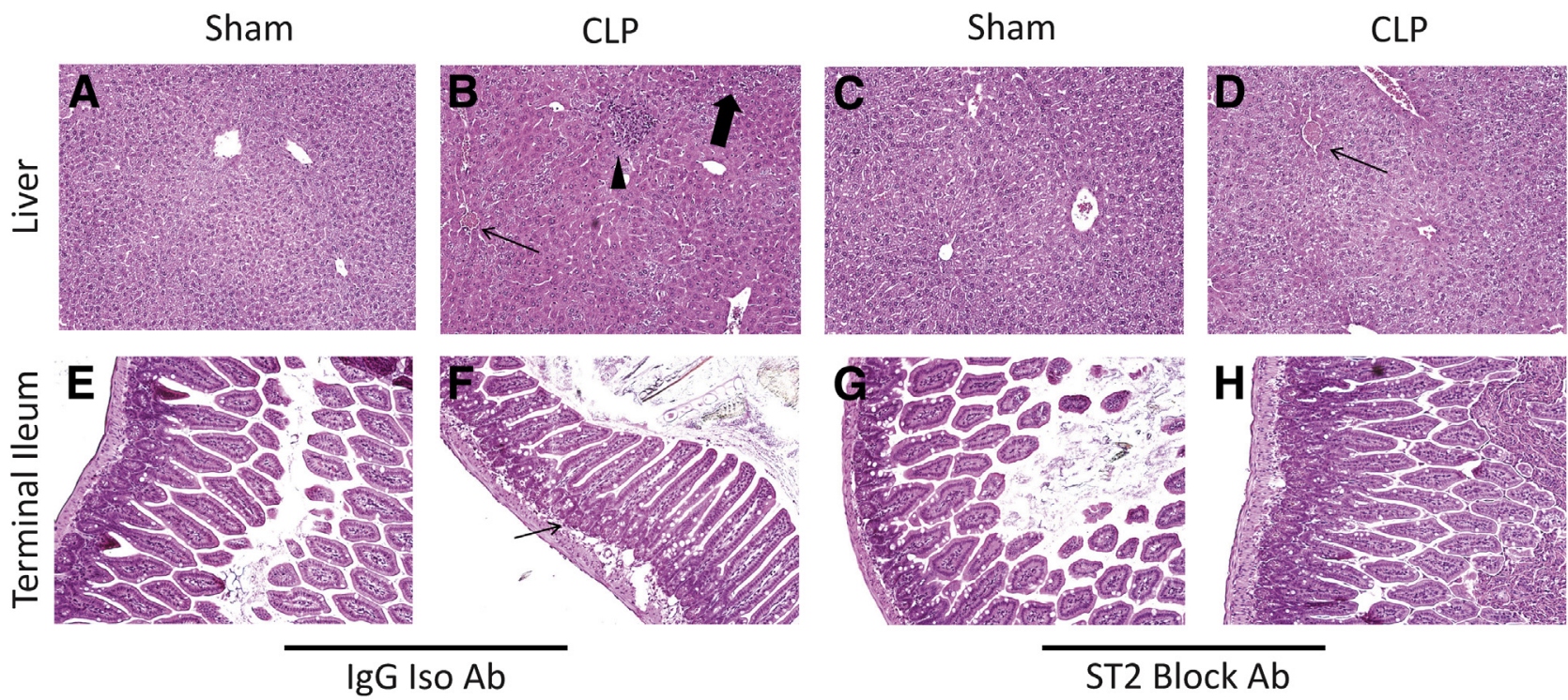

Figure 7 Hematoxylin and eosin staining of the mouse liver (A-D) and the small intestine at the terminal ileum (E-H) in mice treated with IgG isotype (Iso) antibody ( $\mathrm{Ab}$ ) and mice treated with ST2 blocking antibody. B: In the liver of IgG isotype-treated mice, cecal ligation and puncture (CLP) was associated with evidence of venous congestion and dilation (thin arrow), occasional ballooning of hepatocytes (thick arrow), and infiltration of cells forming a microabscess (arrowhead). D: In ST2 blocking antibody-treated mice, the liver maintained considerable integrity and showed only mild changes, including venous congestion and dilation (thin arrow). F: In the terminal ileum of IgG isotype-treated mice, CLP was associated with shortening of the villi, proliferation of goblet cells, and microhemorrhage near the basement membrane (thin arrow). H: In ST2 blocking antibody-treated mice, histologic features were almost identical between the sham and CLP groups. Original magnification, $\times 100$ (light microscopy).

However, we postulate that IL-33 exerts its main effect during the acute septic response as an inducer of Th2-type cytokine production at the site of infection. Of interest, activation of ILC2 response does not appear to be mediated by IL-33 alone. Other known regulators of ILC2 activation, including IL-25 and thymic stromal lymphopoietin, have been shown to be in play at different time points in experimental sepsis in mice. ${ }^{49}$ This may explain why a difference in IL-33 levels was observed in the mouse plasma and peritoneal fluids, but a significant difference in IL-25 levels at the 24-hour mark after sham and CLP surgery was not observed.

The effects of depleting ILC2s has not been extensively reported in the literature, except in experimental models of lung inflammation/asthma research, whereby such depletion was found to lead to limited repair of the airway epithelium and exaggeration of influenza virus-induced airway hyper-responsiveness. This, in large part, is due to ILC2s being able to produce amphiregulin, a member of the epidermal growth factor family. ${ }^{50}$ These findings indicate that mice deficient in IL-13-producing cells, including ILC2s, have improved bacterial clearance and an overall survival advantage in polymicrobial sepsis. These findings, combined with a decreased level of IL-10 at the site of infection in experimental mice, underscore the importance of anti-inflammatory cytokines potentially having a direct impact on sepsis outcome. The improved survival observed in experimental mice, however, may not be solely attributable to the lack of IL-13 at the site of infection. Evidence points to IL-13 having a protective role in the CLP model of sepsis, because it improves the neutrophil influx in tissues after CLP. ${ }^{51}$ IL-13 was used as a way to gauge ILC2 activity in polymicrobial sepsis, and it appears that the role of ILC2 extends far beyond producing anti-inflammatory cytokines. It is possible that ILC2s may also be a key mediator of other regulatory cells in sepsis, but this remains to be investigated.

Note that the experimental mice generated with the Cre/ lox method as described in Materials and Methods would eliminate all IL-13-producing cells, including the Th2 cells, iNKT cells, mast cells, and basophils not specific to the ILC2s. Although the ILC2s may be the primary source of IL-13, the depletion strategy will have a varying effect on these other cell types, because this is the first study to investigate such ablation of IL-13-producing cells in the setting of polymicrobial sepsis. However, the data obtained from transgenic mice in this study have important value because they allude to the function of the ILC2s in sepsis.

Finally, these results suggest that the ILC2 response also can be modulated in vivo by administering IL-33R $\alpha$ (ST2) blocking antibody. A transient, but significant, survival benefit was observed up to 72 hours after CLP in mice treated with the blocking antibody. This is most likely due to the relatively short half-life and/or the duration of blockade provided by the monoclonal antibody given here, as well as the possible antagonism of neutrophil function it may have produced. The ST2 blocking antibody treatment was also able to reduce IL-10 levels at 24 hours after CLP. 
These findings have important therapeutic implications that merit further studies in the future.

\section{Acknowledgment}

\author{
C57B1/6-J $\alpha 18^{-/-}$mice were a gift from Dr. Masaru \\ Taniguchi, (Kanagawa, Japan).
}

\section{Supplemental Data}

Supplemental material for this article can be found at https://doi.org/10.1016/j.ajpath.2018.05.009.

\section{References}

1. Singer M, Deutschland CS, Seymour CW, Shankar-Hari M, Annane D, Bauer M, Bellomo R, Bernard GR, Chiche JD, Coopersmith CM, Hotchkiss RS, Levy MM, Marshall JC, Martin GS, Opal SM, Rubenfeld GD, van der Poll T, Vincent JL, Angus DC: The third international consensus definitions for sepsis and septic shock (sepsis-3). JAMA 2016, 315:801-810

2. Xu J, Kochanek KD, Murphy SL, Tejada-Vera B: Deaths: final data for 2007. Natl Vital Stat Rep 2010, 58:1-19

3. Torio CM, Andrews RM: National Inpatient Hospital Costs: The Most Expensive Conditions by Payer, 2011. HCUP Statistical Brief \#160: Rockville, MD, Agency for Healthcare Research and Quality, 2013

4. Rittirsch D, Flierl MA, Ward PA: Harmful molecular mechanisms in sepsis. Nat Rev Immunol 2008, 8:776-787

5. Tsiotou AG, Sakorafas GH, Anagnostopoulos G, Bramis J: Septic shock; current pathogenic concepts from a clinical perceptive. Med Sci Monit 2005, 11:RA76-RA85

6. Otto GP, Sossdorf M, Claus RA, Rodel J, Menge K, Reinhart K, Bauer M, Riedemann NC: The late phase of sepsis is characterized by an increased microbiological burden and death rate. Crit Care 2011, 15:R183

7. Boomer JS, To K, Chang KC, Takasu O, Osborne DF, Walton AH, Bricker TL, Jarman SD II, Kreisel D, Krupnick AS, Srivastava A, Swanson PE, Green JM, Hotchkiss RS: Immunosuppression in patients who die of sepsis and multiple organ failure. JAMA 2011, 306: 2594-2605

8. Opal SM, Later PF, Francois B, LaRosa SP, Angus DC, Mira JP, Wittlebole X, Dugernier T, Perrotin D, Tidswell M, Jaurequi L, Krell K, Pachl J, Takahashi T, Peckelsen C, Cordasco E, Chang CS, Oeyen S, Aikawa N, Maruyama T, Schein R, Kali AC, Van Nuffelen M, Lynn M, Rossignol DP, Gogate J, Roberts MB, Wheeler JL, Vincent JL; ACCESS Study Group: Effect of eritoran, an antagonist of MD2-TLR4, on mortality in patients with severe sepsis: the ACCESS randomized trial. JAMA 2013, 309:1154-1162

9. Bernard GR, Francois B, Mira JP, Vincent JL, Dellinger RP, Russell JA, Larosa SP, Laterre PF, Levy MM, Dankner W, Schmitt N, Lindemann J, Wittlebole X: Evaluating the efficacy and safety of two doses of the polyclonal anti-tumor necrosis factor-alpha fragment antibody AZD9773 in adult patients with severe sepsis and/or septic shock: randomized, double-blind, placebo-controlled phase IIb study. Crit Care Med 2014, 42:504-511

10. Munford RS, Pugin J: Normal responses to injury prevent systemic inflammation and can be immunosuppressive. Am J Respir Crit Care Med 2001, 163:316-321

11. Venet F, Chung CS, Monneret G, Huang X, Horner B, Garber M, Ayala A: Regulatory $\mathrm{T}$ cell populations in sepsis and trauma. J Leukoc Biol 2008, 83:523-535
12. Hu CK, Venet F, Heffernan DS, Wang YL, Horner B, Huang X, Chung CS, Gregory SH, Ayala A: The role of hepatic invariant NKT cells in systemic/local inflammation and mortality during polymicrobial septic shock. J Immunol 2009, 182:2467-2475

13. Eberl G, Colonna M, D iSanto JP, McKenzie AN: Innate lymphoid cells: a new paradigm in immunology. Science 2015, 348. aaa6566

14. Klose CS, Artis D: Innate lymphoid cells as regulators of immunity, inflammation and tissue homeostasis. Nat Immunol 2016, 17: 765-774

15. Rankin L, Groom J, Mielke LA, Seillet C, Beiz GT: Diversity, function, and transcriptional regulation of gut innate lymphocytes. Front Immunol 2013, 4:22

16. Zhu J: T helper 2 (Th2) cell differentiation, type 2 innate lymphoid cell (ILC2) development and regulation of interleukin-4 (IL-4) and IL-13 production. Cytokine 2015, 75:14-24

17. Salimi M, Barlow JL, Saunders SP, Xue L, Gutowska-Owsiak D, Wang X, Huang LC, Johnson D, Scanlon ST, McKenzie AN, Fallon PG, Ogg GS: A role for IL-25 and IL-33-driven type-2 innate lymphoid cells in atopic dermatitis. J Exp Med 2013, 210:2939-2950

18. Walker JA, McKenzie AN: Development and function of group 2 innate lymphoid cells. Curr Opin Immunol 2013, 25:148-155

19. Ho J, Bailey M, Zaunders J, Mrad N, Sacks R, Sewell W, Harvey RJ: Group 2 innate lymphoid cells (ILC2s) are increased in chronic rhinosinusitis with nasal polyps or eosinophilia. Clin Exp Allergy 2015, 45:394-403

20. Scanlon ST, McKenzie AN: Type 2 innate lymphoid cells: new players in asthma and allergy. Curr Opin Immunol 2012, 24:707-712

21. Hams E, Armstrong ME, Barlow JL, Saunders SP, Schwartz C, Cooke G, Fahy RJ, Crotty TB, Hirani N, Flynn RJ, Voehringer D, McKenzie AN, Donnelly SC, Fallon PG: IL-25 and type 2 innate lymphoid cells induce pulmonary fibrosis. Proc Natl Acad Sci U S A 2014, 111:367-372

22. Ayala A, Deol ZK, Lehman DL, Herdon CD, Chaudry IH: Polymicrobial sepsis but not low-dose endotoxin infusion causes decreased splenocyte IL-2/IFN-gamma release while increasing IL-4/IL-10 production. J Surg Res 1994, 56:579-585

23. Cui J, Shin T, Kawano T, Sato H, Kondo E, Toura I, Kaneko Y, Koseki H, Kanno M, Taniguchi M: Requirement for Valpha14 NKT cells in IL-12-mediated rejection of tumors. Science 1997, 278: $1623-1626$

24. Baker CC, Chaudry IH, Gaines HO, Baue AE: Evaluation of factors affecting mortality rate after sepsis in murine cecal ligation and puncture model. Surgery 1983, 94:331-335

25. Committee for the Update of the Guide for the Care and Use of Laboratory Animals; National Research Council: Guide for the Care and Use of Laboratory Animals: Eighth Edition. Washington, DC, National Academies Press, 2011

26. Levy MM, Fink MP, Marshall JC, Abraham E, Angus D, Cook D, Cohen J, Opal SM, Vincent J-L, Ramsay G: 2001 SCCM/ESICM/ACCP/ATS/SIS international sepsis definitions conference. Intens Care Med 2003, 29:530-538

27. Wesche-Soldato DE, Chung CS, Gregory SH, Salazar-Mather TP, Ayala CA, Ayala A: $\mathrm{CD}^{+} \mathrm{T}$ cells promote inflammation and apoptosis in the liver after sepsis: role of Fas-FasL. Am J Pathol 2007, 171:87-96

28. Meldrum DR, Ayala A, Perrin MM, Ertel W, Chaudry IH: Diltiazem restores IL-2, IL-3, IL-6, and IFN-gamma synthesis and decreases susceptibility to sepsis following hemorrhage. J Surg Res 1991, 51: $158-164$

29. Halim TY, Takei F: Isolation and characterization of mouse innate lymphoid cells. Curr Protoc Immunol 2014, 106:3.25.1-3.25.13

30. Price AE, Liang HE, Sullivan BM, Reinhardt RL, Eisley CJ, Erie DJ, Locksley RM: Systemically dispersed innate IL-13-expressing cells in type 2 immunity. Proc Natl Acad Sci U S A 2010, 107: 11489-11494

31. Gronke K, Kofoed-Nielsen M, Dieenbach A: Isolation and flow cytometry analysis of innate lymphoid cells from the intestinal lamina 
propria. Inflammation. Methods in Molecular Biology, vol 1559. Edited by Clausen B, Laman J. New York, NY: Humana Press, 2017. pp. $255-265$

32. Ayala A, Perrin MM, Kisala JM, Ertel W, Chaudry IH: Polymicrobial sepsis selectively activates peritoneal but not alveolar macrophages to release inflammatory mediators (interleukins-1 and 6 and tumor necrosis factor). Circ Shock 1992, 36:191-199

33. Heffernan DS, Monaghan SF, Thakkar RK, Tran ML, Chung CS, Gregory SH, Cioffi WG, Ayala A: Inflammatory mechanisms in sepsis: elevated invariant natural killer T-cell numbers in mouse and their modulatory effect on macrophage function. Shock 2013, 40:122-128

34. Lee WY, Moriarty TJ, Wong CH, Zhou H, Strieter RM, van Rooijen N, Chaconas G, Kubes P: An intravascular immune response to Borrelia burgdorferi involves Kupffer cells and iNKT cells. Nat Immunol 2010, 11:295-302

35. Hashiguchi M, Kashiwakura Y, Kojima H, Kobayashi A, Kanno Y, Kobata T: IL-33 activates eosinophils of visceral adipose tissue both directly and via innate lymphhoid cells. Eur J Immunol 2015, 45: 876-885

36. Spooner CE, Markowitz NP, Saravolatz LD: The role of tumor necrosis factor in sepsis. Clin Immunol Immunopathol 1992, 62: S11-S17

37. Blackwell TS, Christman JW: Sepsis and cytokines: current status. Br J Anaesth 1996, 77:110-117

38. Silva AT, Cohen J: Role of interferon-gamma in experimental gramnegative sepsis. J Infect Dis 1992, 166:331-335

39. Angus DC: The search for effective therapy for sepsis: back to the drawing board? JAMA 2011, 306:2614-2615

40. Monneret G, Venet F, Pachot A, Lepape A: Monitoring immune dysfunction in the septic patient: a new skin for the old ceremony. Mol Med 2008, 14:64-78

41. Novotny AR, Reim D, Assfalq V, Altmahr F, Friess HM, Emmanuel K, Holzmann B: Mixed antagonist response and sepsis severity-dependent dysbalance of pro- and anti-inflammatory responses at the onset of postoperative sepsis. Immunobiology 2012, 217:616-621

42. Young JS, Heffernan DS, Chung CS, Kettenman ML, Young WA, Guillen VS, Cioffi WG, Ayala A: Effect of PD-1:PD-L1 in invariant natural killer T-cell emigration and chemotaxis following sepsis. Shock 2016, 45:534-539

43. Wang P, Chaudry IH: Mechanism of hepatocellular dysfunction during hyperdynamic sepsis. Am J Physiol 1996, 270:R927-R938

44. Oboki K, Ohno T, Kajiwara N, Arae K, Morita H, Ishii A, Nambu A, Abe T, Kiyonari H, Matsumoto K, Sudo K, Okumura K, Saito H, Nakae S: IL-33 is a crucial amplifier of innate rather than acquired immunity. Proc Natl Acad Sci U S A 2010, 107:18581-18586

45. Pichery M, Mirey E, Mercier P, Lefrancais E, Dujardin A, Ortega N, Girard J-P: Endogenous IL-33 is highly expressed in mouse epithelial barrier tissues, lymphoid organs, brain, embryos, and inflamed tissues: in situ analysis using a novel IL-33-LacZ gene trap reporter strain. J Immunol 2012, 188:3488-3495

46. Chang D, Jia J, Zang B: [Changes in plasma interleukin-33 concentrations in sepsis and its correlation with seriousness of sepsis]. Chinese. Zhonghua Wei Zhong Bing Ji Jiu Yi Xue 2015, 27: $138-142$

47. Alves-Filho JC, Sonego F, Souto FO, Freitas A, Verri WA Jr, Auxiliadora-Martins M, Basile-Filho A, McKenzie AN, Xu D, Cunha FQ, Liew FY: Interleukin-33 attenuates sepsis by enhancing neutrophil influx to the site of infection. Nat Med 2010, 16:708-712

48. Li S, Zhu FX, Zhao XJ, An YZ: The immunoprotective activity of interleukin-33 in mouse model of cecal ligation and puncture-induced sepsis. Immunol Lett 2016, 169:1-7

49. Kuethe JW, Prakash PS, Midura EF, Johnson BL III, Kasten KR, Caldwell CC: Thymic stromal lymphopoietin mediates the host response and increases mortality during sepsis. J Surg Res 2014, 191: $19-24$

50. Monticelli LA, Sonnenberg GF, Abt MC, Alenghat T, Ziegler CG, Doering TA, Angelosanto JM, Laidlaw BJ, Yang CY, Sathaliyawala T, Kubota M, Turner D, Diamond JM, Goldrath AW, Farber DL, Collman RG, Wherry EJ, Artis D: Innate lymphoid cells promote lung-tissue homeostasis after infection with influenza virus. Nat Immunol 2011, 12:1045-1054

51. Matsukawa A, Hogaboam CM, Lukacs NW, Lincoln PM, Evanoff HL, Strieter RM, Kunkel SL: Expression and contribution of endogenous IL-13 in an experimental model of sepsis. J Immunol 2000, 164:2738-2744 